\title{
Uso de varenicline no tratamento do tabagismo: relato de dois casos
}

\author{
Use of varenicline in smoking cessation: two case reports
}

\author{
Fabiano Coelho Horimoto', Mariele Bevilaqua ${ }^{2}$ \\ ${ }^{1}$ Professor-colaborador, Universidade Federal de Mato Grosso do Sul (UFMS), Campo Grande, MS. ${ }^{2}$ Acadêmica de Medicina, Universidade Federal \\ de Santa Maria (UFSM), Santa Maria, RS. \\ Estudo realizado no Serviço de Psiquiatria, Faculdade de Medicina, UFMS.
}

\section{Resumo}

O objetivo deste trabalho foi antecipar informações sobre uma droga que está sendo lançada no combate ao tabagismo, auxiliando aqueles que desejam parar de fumar. O varenicline atua no sistema nervoso central, ligando-se ao receptor nicotínico alfa4beta2 e proporcionando redução do prazer que o cigarro provoca. É um mecanismo de ação novo, que nenhum psicofármaco atinge. Os estudos têm mostrado superioridade do varenicline em manter taxas mais altas e prolongadas de abstinência, quando comparado à bupropiona e placebo. Caso 1: Homem, 51 anos, mais de 30 anos de tabagismo. Nunca atingiu abstinência superior a algumas semanas. Utilizou varenicline na dose preconizada e, na $12^{\mathrm{a}}$ semana, quando podia interromper, resolveu manter o fármaco até completar 24 semanas de tratamento. Está abstinente há 8 meses. Caso 2 Mulher, 48 anos, 30 anos de dependência do tabaco. Há 21 anos, parou espontaneamente na gestação da única filha e, após 6 meses, recaiu. Usou varenicline por 12 semanas associado à terapia cognitivo-comportamental. Há 7 meses, está abstinente. Os tratamentos disponíveis até o momento são incipientes em promover altos índices de abstinência no primeiro ano. Portanto, a abordagem engloba um conjunto de estratégias, como disponibilizar drogas de primeira linha, além de medidas e projetos que apóiem não só o parar de fumar, mas o continuar abstinente. O tratamento do tabagismo requer investimento público; do contrário, drogas como o varenicline vão beneficiar apenas uma pequena parcela da população.

Descritores: Varenicline, tratamento, tabaco, cigarro.

\begin{abstract}
The objective of this study was to provide information about a new drug to help people quit smoking. Varenicline acts on the central nervous system and binds to the alph4beta 2 nicotine receptor, reducing the sensation of pleasure caused by smoking. Its mechanism of action is unique, different from any other psychotropic. Studies have shown that, when compared with bupropion and placebo, varenicline is more effective in maintaining smoking abstinence and for longer periods of time. Case 1: A 51-year-old male patient who has been smoking for more than 30 years. He has never been more than a few weeks without smoking. He used the recommended dose of varenicline and, although he could have stopped after 12 weeks, preferred to follow the treatment for 24 weeks. He has been abstinent for 8 months. Case 2: 48 -year-old female who has been tobacco dependent for 30 years. She quit during the pregnancy of her daughter 21 years ago, but started again 6 months later. She used varenicline for 12 weeks associated with cognitive-behavioral therapy. She has been abstinent for 7 months. Currently available treatments still have limited effectiveness in assuring high abstinence rates over the first year. Therefore, our approach includes several strategies, such as administration of first-line drugs, besides measures and projects that not only help patients quit smoking, but also remain abstinent. Anti-smoking treatments require large investments from the government. Otherwise, new drugs, such as varenicline, will only benefit a few segments of the population.
\end{abstract} Keywords: Varenicline, treatment, tobacco, cigarette. 


\section{Introdução}

O tabagismo representa na atualidade o mais sério problema de saúde pública que a maioria dos países enfrenta, por seus efeitos comprovados no surgimento e agravamento de dezenas de doenças. Segundo a Organização Mundial da Saúde ${ }^{1}$, o tabagismo é responsável por 4,9 milhões de mortes por ano.

Em dados de $1988^{2}$, do Relatório do Ministério de Saúde Norte-Americano, os custos relacionados a doenças provocadas pelo tabaco somaram 1 bilhão de dólares por dia. No Brasil ${ }^{1}$, atualmente, morrem cerca de 200.000 pessoas por ano por doenças relacionadas diretamente ao hábito de fumar. Portanto, além de ser uma dependência extremamente letal, o tabagismo praticamente atinge o mundo inteiro, expondo todos os governos ao enfrentamento desse problema. Por ceifar milhões de vidas anualmente, é considerado a maior causa isolada evitável de mortes precoces. Como afirma Silva ${ }^{3}$, o tabaco é, junto com o álcool, a droga social por excelência do mundo moderno.

Segundo Frances \& Franklin $\mathrm{Jr}^{4}$, o álcool e o tabaco continuam sendo as substâncias mais usadas e abusadas e as que impõem maior risco à saúde. É notório também o uso do tabaco por parte de populações especiais, como os doentes mentais. $\mathrm{O}$ cigarro reduz o nível plasmático de várias drogas, como os antipsicóticos e antidepressivos, devido à indução de enzimas hepáticas que as metabolizam ${ }^{5}$.

Os dados do Relatório do Ministério de Saúde Norte-Americano ${ }^{2}$ apontam que, na psiquiatria, até $50 \%$ dos deprimidos ambulatoriais fumam, além de $70 \%$ dos bipolares e 90\% dos esquizofrênicos. Pesquisando pacientes psiquiátricos em São Paulo, Ratto et al. ${ }^{6}$ observaram o mesmo aumento de prevalência nessa população. Portanto, o psiquiatra está numa condição ímpar de abordar essa população e encorajá-los a parar de fumar.

\section{Relato de caso}

\section{Caso 1}

Paciente de 51 anos, masculino, no segundo casamento, natural do Rio Grande do Sul e procedente de Campo Grande. Tabagista desde os 16 anos, quando já referia consumo de 20 cigarros ao dia. Fez primeira tentativa de interrupção há cerca de 2 anos, ficando abstinente com acompanhamento de equipe multiprofissional em Porto Alegre, por cerca de 40 dias. Seu médico na época fez diagnóstico de transtorno afetivo bipolar associado a uso abusivo de álcool. Em março de 2006, de volta a Campo Grande, internou-se em clínica de repouso por 1 semana, mas no dia da alta voltou a fumar. Nível de dependência segundo a Escala de Fagerström ${ }^{7}$ : elevado (seis pontos).

Sua esposa e o mesmo procuraram assistência psiquiátrica há 11 meses, e, devido ao descontrole em relação à ingesta alcoólica, houve nova internação no nosocômio anterior. Durante as visitas, foi-lhe explicada a possibilidade de se utilizar varenicline, e o paciente se mostrou receptivo ao uso da nova droga. Sua motivação principal, naquele momento, devia-se ao comprometimento pulmonar, pois já havia início de processo enfisematoso.

Ao sair do hospital após 10 dias, estava em uso de oxcarbazepina $900 \mathrm{mg}$, escitalopram $20 \mathrm{mg}$, alprazolam $1 \mathrm{mg}$ e dissulfiram $250 \mathrm{mg}$. Na mesma semana, encomendou a medicação e, no início de setembro de 2006, fez o primeiro esquema terapêutico por 12 semanas, conforme recomendado na bula ${ }^{8}$. Não apresentou recaída, foi rigorosamente fiscalizado pela esposa quanto ao consumo de álcool e tabaco, e esta administrava as medicações. Não observou nenhum efeito adverso. Em dezembro, resolveu continuar o varenicline, após as 12 primeiras semanas. Quando completou 24 semanas de uso, programamos uma retirada gradual em 1 semana, a pedido do paciente. Apresenta-se abstinente há 8 meses e há 2 meses sem usar varenicline. Sente-se bem melhor em relação a seu estado geral e respiratório.

\section{Caso 2}

Paciente de 48 anos, do sexo feminino, divorciada, natural de Santa Catarina, procedente de Campo Grande. Tabagista “desde adolescente", não se recorda com precisão do início do uso, mas quando estava na faculdade (entrou com 18 anos) já fumava uma carteira por dia. Aos 30 anos, interrompeu o uso durante a gestação do único filho, sem tratamento específico, voltando a fumar após cerca de 6 meses do nascimento. Desde então, faz tentativas infrutíferas e ocasionais para interromper, não durando mais que algumas semanas. Recentemente, devido à insistência do atual companheiro, não-fumante, tentou parar usando adesivo de nicotina associado a bupropiona na dose de $300 \mathrm{mg}$ ao dia, mas ficou abstinente por 3 semanas, atribuindo a recaída à "vontade de sentir novamente o prazer do cigarro". Nível de dependência segundo a Escala de Fagerström ${ }^{7}$ : muito elevado (oito pontos).

Em outubro de 2006, iniciou o varenicline na posologia de $0,5 \mathrm{mg}$, uma vez ao dia, dobrando a dose após 7 dias, quando parou de fumar. Sentiu secura na boca nos primeiros dias. Há 3 meses, interrompeu a medicação por conta do custo elevado, completando 12 semanas de uso contínuo de $1 \mathrm{mg}$ da droga (a posologia indicada pelo laboratório é de $2 \mathrm{mg}$ do oitavo dia até completar 12 semanas) e, desde então, está 
abstinente, não sentindo desejo ou compulsão para fumar. Paralelamente, realiza terapia cognitivocomportamental há cerca de 9 meses e sente que essa abordagem tem ajudado bastante no tratamento.

\section{Discussão}

Os tratamentos farmacológicos atuais, via de regra, seguem diferentes mecanismos de ação no sistema nervoso central, provocando alguma alteração que possa ser positiva no indivíduo abstinente, reduzindo o desejo de fumar, como alguns antidepressivos, ou mimetizando o efeito da própria nicotina, como nos adesivos e chicletes 9 . Todas as terapêuticas oferecidas lidam com taxas de abstinência extremamente desapontadoras em médio prazo (6 meses).

As drogas mais utilizadas são:

a) Bupropiona ${ }^{10}$ : é uma medicação com ação pródopaminérgica, que age no circuito de gratificação cerebral devido à liberação aguda de dopamina no nucleo accumbens, responsável pelo efeito prazeroso do cigarro. Porém, o tabaco possui ação aguda e muito mais potente como liberador de dopamina, sendo tênue esse efeito por parte da bupropiona.

b) Nortriptilina ${ }^{11}$ : menos utilizada, trabalhos apontam abstinência de 6 meses em $20 \%$ dos pacientes que a usaram, contra $5 \%$ do grupo que tomou placebo. É considerada uma droga de segunda linha, mas com custo vantajoso. Não possui um mecanismo de ação específico que favoreça esse tratamento; os defensores dessa linha terapêutica postulam que a modulação do humor e ansiedade e a redução da irritabilidade que a droga proporciona em muitos dos indivíduos abstinentes possam impedir recaídas precoces. Mas nem todos terão benefícios dessa conduta ou sentirão esses efeitos.

c) Terapia de reposição de nicotina (TRN) associada com terapia cognitivo-comportamental (TCC): essa associação pode ser útil em muitos casos. Segundo Gilbert \& Warburton, apud Pedroso et al. ${ }^{12}$, com o acréscimo da abordagem não-farmacológica, há a possibilidade de incentivar mudanças permanentes, como parar de fumar. Em relação à TRN, muitos estudos ${ }^{13,14}$ têm observado uma eficácia maior na redução do número de cigarros consumidos em comparação à abstinência total. Sabemos que a redução dos riscos para as doenças relacionadas ao tabaco é mínima ou inexistente em indivíduos que diminuem a quantidade total de cigarros diários, mas continuam fumando.

Com o advento do varenicline, lançado este ano, finalmente obteve-se uma droga que, pela sua ação, propicia maiores possibilidades de eficácia na promoção de taxas maiores e mais prolongadas de abstinência. Esse psicofármaco age como agonista parcial do receptor nicotínico alfa4beta $2^{15}$, justamente o responsável pela vontade de fumar, pela ansiedade e pelo craving, enquanto seu antagonismo provoca redução no prazer de fumar.

Uma metanálise de $\mathrm{Wu}$ et al. ${ }^{16}$, com 70 artigos analisados relatando os resultados de estudos controlados com placebo, indicou superioridade do varenicline em relação à bupropiona, terapia de reposição nicotínica e placebo, no período de 1 ano. Nides et al. ${ }^{17}$ observaram, em 4 semanas, taxas de abstinência de $48 \%$ no grupo que usou $2 \mathrm{mg}$ de varenicline e de $37 \%$ no grupo que usou $1 \mathrm{mg}$, contra $17 \%$ que usaram placebo.

Em seguimentos mais longos, como realizados por Oncken et al. ${ }^{18}$, o decréscimo na eficácia é esperado, mas, ainda assim, 22,4\% dos pacientes deste estudo que usaram $1 \mathrm{mg}$ de varenicline estavam abstinentes, contra $18,5 \%$ que usaram $0,5 \mathrm{mg}$ e $3,9 \%$ que usaram placebo.

Nos dois casos em questão, os pacientes referiram claramente uma redução acentuada no desejo de fumar, em comparação a outras tentativas que fizeram. Apesar do período curto de abstinência que estão completando $(8$ e 7 meses, respectivamente), o resultado desses relatos mostrase promissor para encorajar o médico e o doente a enfrentarem esse tratamento como um método realmente eficaz para muitos pacientes.

Portanto, novas drogas que venham ampliar o arsenal terapêutico no tratamento do tabagismo são medidas valiosas e indispensáveis no enfrentamento deste grave problema, e esperamos que, num futuro breve, o índice de indivíduos fumantes caia consideravelmente.

\section{Referências}

1. Gigliotti AP, Presman S. Apresentação. In: Gigliotti AP, Presman S. Atualização no tratamento do tabagismo. Rio de Janeiro: ABP Saúde; 2006. p. 7.

2. Kaplan HI, Sadock BJ, Grebb JA. Transtornos relacionados à substâncias. In: Kaplan HI, Sadock BJ, Grebb JA, eds. Compêndio de psiquiatria. $7^{\text {a }}$ ed. Porto Alegre: Artmed; 2005. p. 419-22.

3. da Silva MS. Se liga! O livro das drogas. Rio de Janeiro: Record; 1997. p. 71-86.

4. Frances RJ, Franklin JR JE. Transtornos por uso de álcool e outras substâncias psicoativas. In: Talbot J, Hales R, Yudofsky S, eds. Tratado de psiquiatria. Porto Alegre: Artmed; 1992. p. 235.

5. Salgado CAI, Zubaran C, Abreu PB. Interações farmacológicas relevantes entre drogas de abuso e psicofármacos. In: Marcolin MA, ed. Interações farmacológicas com drogas psiquiátricas. Rio de Janeiro: Medsi; 1988. p. 227.

6. Ratto RLC, Gullnelli A, Menezes PR. Prevalência de tabagismo em pessoas com transtornos mentais graves na cidade de São Paulo. Rev Bras Psiq. 2004;26(Supl II):11-20.

7. Fagerström KO. Measuring degree of physical dependence to tobacco smoking with reference to individualization of treatment. Addict Behav. 1978;3(3/4):235-41. 
8. Chantix. 2006. Avaiable at: http://www.CHANTIX.com.

9. Meirelles RHH, Cavalcante TM. Quais políticas de controle de tabagismo um país deve ter para chegar a um tratamento eficaz? In: Gigliotti AP, Presman S. Atualização no tratamento do tabagismo. Rio de Janeiro: ABP Saúde; 2006. p. 184.

10. Horimoto FC, Fontão MF, Pinto MA. Uso de Antidepressivos pelo clínico. In: Horimoto FC, Ayache DCG, Souza JÁ, eds. Depressão: diagnóstico e tratamento pelo clínico. São Paulo: Roca; 2005. p. 139.

11. Gigliotti AP, Oliveira LL, Laranjeira R. Tratamento do tabagismo. In: Gigliotti AP, Presman S. Atualização no tratamento do tabagismo. Rio de Janeiro: ABP Saúde; 2006. p. 87.

12. Pedroso RS, Oliveira MS, Araújo RB, Castro MG, Melo WV. Expectativas de resultados frente ao uso de álcool, maconha e tabaco. Rev Psiquiatr RS. 2006;28(2):198-206.

13. Etter JF, Laszlo E, Zellweger JP, Perrot C, Perneger TV. Nicotine replacement to reduce cigarette consumption in smokers who are unwilling to quit: a randomized trial. J Clin Psychopharmacol. 2002;22(5):487-95.

14. Wennike P, Danielsson T, Landfeldt B, Westin A, Tonnessen P. Smoking reduction promotes smoking cessation: results from a double-blind, randomized placebo-controlled trial of nicotine gun with a 2-year follow-up. Addiction. 2003;98(10):1395-402.

15. Coe JW, Brooks PR, Veteline MG, Wirtiz WO, O’Neill BT, Sands SB. Varenicline (CP-526,555): a novel, potent and selective nicotinic receptor partial agonist for the treatment of smoking cessation. In: Colby SM, Drobes DJ, West R, eds. Proceedings of the SRNT's 11th Annual Metting and 7th Annual European Conference. Praga, Rep Tcheca; 2005. Nicotine Tob Res. 2005;7(4):667-709.

16. Wu P, Wilson K, Dimoulas P, Mills EJ. Effectiveness of smoking cessation therapies: a systematic review and meta-analysis. BMC Public Health. 2006;6:300.

17. Nides M, Oncken C, Gonzales D, Rennard S, Watsky EJ, Anziano $\mathrm{R}$, et al. Smoking cessation with varenicline, a selective alpha4beta2 nicotinic receptor partial agonist: results from a 7-week, randomized, placebo and bupropion-controlled trial with 1-year follow-up. Arch Intern Med. 2006;166(15):1561-8.

18. Oncken C, Gonzales D, Nides M, Rennard S, Watsky E, Billing CB, et al. Efficacy and safety of the novel selective nicotinic acetylcholine receptor partial agonist, varenicline, for smoking cessation. Arch Intern Med. 2006;166(15):1571-7. 